\title{
La elite en entredicho: escándalos familiares, difamación y deshonor en Santiago de Chile en el ocaso del siglo XIX
}

\author{
Verónica Undurraga Schüler ${ }^{1}$ \\ Recibido: 28 de enero de 2019 - Aprobado: 15 de abril de 2019
}

\begin{abstract}
Resumen:
A través del contencioso proceso de separación y de divorcio de dos sujetos de elite en el Santiago de Chile de fines del siglo XIX, en este artículo se analizan las formas de administrar el escándalo en un contexto histórico en el que la asimilación del honor a la reputación otorgó mayor visibilidad a este fenómeno. Entendiendo que el escándalo no surgía solo del hecho transgresivo en sí mismo, sino de su representación como suceso escandaloso por una sociedad que actuaba activamente en su construcción, se propone que este estuvo sujeto a una serie de usos e intereses. Esto último permite poner en evidencia los mecanismos mediante los cuales los sujetos históricos intentaron elaborar o evitar, construir o controlar y, luego, administrar en beneficio propio las repercusiones del conocimiento público de prácticas que podrían ser catalogadas de escandalosas, incidiendo en la definición de su imagen social.
\end{abstract}

Palabras clave: escándalo, honor, difamación, emociones

\section{The Elite in Crisis: Family Scandals, Defamation and Dishonor in Santiago, Chile at the End of the 19th Century}

\begin{abstract}
After the contentious process of separation and divorce of two members of the elite in Santiago, Chile, at the end of the $19^{\text {th }}$ century, this article analyzes how the scandal was dealt with in a historical context where the assimilation of honor within reputation gave greater visibility to this phenomenon. With the understanding that the scandal did not arise merely due to the trans-
\end{abstract}

Este trabajo es producto del proyecto FONDECYT Regular № 1160501 "Administrando el escándalo: honor y reputación en Chile, 1840-1920" y de AEl Proyecto de investigación I+D "La vida emocional de las mujeres: experiencias del mundo, formas de la sensibilidad. Europa y América, siglos XVII-XIX" HAR2015-63804-P.

1 Chilena. Doctora en Historia, Pontificia Universidad Católica de Chile. Académica Instituto de Historia, Pontificia Universidad Católica de Chile. E-mail: vundurra@uc.cl 
gressive event but from its representation as a scandalous event by a society participating actively in its construction, it is proposed that this scandal was subject to a number of uses and interests. This brings to light the mechanisms by which historical figures attempted to create or avoid, construct or control, and manage for one's own benefit the repercussions of public knowledge of practices that could be considered scandalous, thus influencing the definition of one's own social image.

Keywords: scandal, honor, defamation, emotions

\begin{abstract}
"es que la señora Prevost me ha perseguido con su sistema de difamación en todas partes, que ha empleado para conseguir ese objeto todos los medios, que sólo una mujer mal apasionada sabe emplear [...] destrozando la familia, incendiando el hogar, desacreditando al esposo, sacrificando para siempre a los hijos, haciendo de todo el pasado un montón de cenizas" (Godoy, 1888: 8).
\end{abstract}

El 26 de julio de 1887, doña Mariana Prevost Moreira (1852-1920) -dama de la alta aristocracia limeña y dueña de una importante fortuna-, huyó de madrugada del hogar que compartía con su esposo en Santiago de Chile (Figueroa, 1929: 326-327). ${ }^{2}$ En compañía de su hija mayor se presentó a las primeras horas de la mañana en la puerta de la casa de Don Agustín Edwards Ross y, al conocer que su esposa se encontraba en Valparaíso, se dirigió a la casa del señor Uriburu, ministro de la República Argentina, también en busca de la mujer de este último. Su periplo terminó con ella internada en el Hospital San Borja, donde fue acogida gracias a la intervención del Arzobispo de Santiago, Mariano Casanova. ${ }^{3}$

Según indicara casi un año más tarde don Joaquín Godoy Cruz, esposo de Mariana, en su "Alegato de Bien Probado" presentado en el marco del juicio de divorcio perpetuo interpuesto por Prevost, luego de abandonar el hogar común, Mariana "se acogió a un hospital, se echó a la cama, se supuso postrada como lo dijo en sus escritos i consiguió hacer de este establecimiento de caridad un sitio de romería para algunas personas piadosas o

2 Hija de Samuel Stanhope Prevost Smith -ministro de Estados Unidos en Lima- y de María Mauricia Moreyra y Avellafuerte. Mariana Prevost era dueña de una gran fortuna, la que se evidencia, por ejemplo, en su aporte de 69 mil pesos a su matrimonio, lo que nos consta a partir de los documentos de la liquidación conyugal. ARNAD, Fondo Conservador de Bienes Raíces de Santiago, Vol. 87, fj. 28 y Vol. 94, fj. 416.

3 En el juicio de divorcio perpetuo interpuesto por Mariana Prevost, el Arzobispo Casanova habría señalado que "dio en favor de la señora Prevost una orden para su recepción en la casa del Buen Pastor, porque le hizo entender que de otro modo se seguirán mayores males" (Godoy, 1888: 40). 
inconscientes o otras [sic] que andaban a caza de novedades o de escándalos" (Godoy, 1888: 8). ${ }^{4}$

Para Joaquín Godoy, el "acogerse a un hospital", "echarse a la cama" y "suponerse postrada", formaban parte de una serie de estrategias performativas de su esposa, representada como una mujer astuta, calculadora y manipuladora de su entorno social. ${ }^{5}$ Mariana Prevost habría protagonizado una obra teatral, un drama que la instalaba como víctima de un espectáculo -"escandalosa campanada" - en el que habría participado toda la élite santiaguina como espectadora de un escándalo de grandes proporciones (Godoy, 1888: 7).

Desde la perspectiva de su esposo, en la puesta en escena que precedió y luego se ejecutó durante el abandono del hogar común, la señora Prevost habría hecho uso de la palabra -a través de rumores y chismes-, de la escritura -por medio de la circulación de anónimos-, y de acciones -tales como "hacerse la mendiga" ante sus amigas-, para producir un "sistema de difamación" con el fin de propiciar el "descrédito", el "desprestigio" y el "deshonor" de Joaquín Godoy (Godoy, 1888: 54, 98; Piwonka, 1929: 30). A través de estos gestos y palabras, Prevost habría generado transformaciones en el entorno social que llevaron a Godoy a escribir y luego publicar y hacer circular su "Alegato de Bien Probado" entre la elite de Santiago.

Este alegato, de ciento ocho páginas, correspondía al derecho que tenía cada parte en juicio de recapitular las razones jurídicas relacionadas con la contestación de la demanda y de las pruebas rendidas en el proceso. El alegato de Joaquín Godoy no solo fue presentado a la justicia, sino que también fue enviado a imprimir por él con el objetivo de reivindicar su honor ante la elite de Santiago. La práctica de imprimir y hacer circular partes de los procesos judiciales era habitual cuando se trataba de juicios de alta connotación pública y constituía uno de los soportes privilegiados para administrar el escándalo por sus protagonistas masculinos.

Dichos "folletos" consistían en impresos de entre diez y setenta páginas, aunque también podían sobrepasar las cien carillas, que se hacían circular para dar publicidad a un planteamiento o para rebatir alguna idea. Aunque

4 Según la Ley de Matrimonio Civil de 1884, el divorcio no disolvía el matrimonio, sino que suspendía la vida común de los cónyuges. Algunas de las causales del artículo 21, como la ausencia de uno de los esposos, por más de tres años sin causa justa, no eran suficientes para decretar el divorcio perpetuo (Ley de Matrimonio Civil, 1884, artículo 21, causales 5-8 y 12).

5 Entendemos performatividad a partir del filósofo del lenguaje J. L. Austin, que supone una conexión obligada entre lenguaje y acción, al constatar la capacidad de algunas expresiones de convertirse en acciones y transformar el entorno. A la vez, dialogamos con la propuesta de Judith Butler, en el sentido de comprender las acciones y los cuerpos como performativos cuando generan realidades a partir de las transformaciones de las mismas (Austin: 1962; Butler: 1993). 
estos podían abordar temas muy diversos, hemos comprobado la existencia de un importante número de ellos destinados a defender la honra personal o a desprestigiar la ajena. Titulados como "refutaciones", "vindicaciones" y "defensas", estos impresos discurrían sobre la conducta de sujetos en tanto particulares o como funcionarios públicos.

Si bien el expediente del juicio de divorcio perpetuo entre Mariana Prevost y Joaquín Godoy no ha podido ser hallado, contamos con documentos que permiten reconstruir la historia de su contencioso proceso de separación y de divorcio, que es lo que nos interesa en este trabajo. Por una parte, contamos con el mencionado "Alegato de Bien Probado", escrito por Godoy, y que, si bien presenta una visión parcial -y evidentemente masculina- de los hechos, si lo hacemos dialogar con otras fuentes, como la larga sentencia de divorcio, nos permiten analizar el objeto de estudio del presente artículo (Gaceta de los Tribunales, 1889, tomo II, No 3047: 428; Piwonka, 1929: 29-36). ${ }^{6}$

A lo largo de este trabajo, y a través de este escándalo matrimonialfamiliar con repercusiones en la imagen pública de un connotado político, analizaremos las formas de administrar el escándalo en un contexto histórico en el que la asimilación del honor a la reputación otorgó mayor visibilidad a este fenómeno. Proponemos que en el Santiago de Chile de fines del siglo XIX las elites movilizaron un conjunto de estrategias individuales, familiares y/o de grupo con el fin de administrar el potencial escándalo como elemento dañino para la reputación. En una primera instancia, se intentaba contener en la esfera privada a través de mecanismos de control parental y familiar $y$, en segunda instancia, al adquirir notoriedad pública, se enfrentaba a través del uso de la palabra, del impreso y de la justicia. ${ }^{7}$ Asimismo, postulamos que existían diferencias de género en la administración del escándalo, observándose la tendencia femenina a usar el rumor y los contactos personales, en tanto que los hombres recurrían a la opinión pública, incluso mediante de la publicación de impresos.

\section{Un escándalo en el seno de la elite}

El perfil público de la disputa se alimentó de la alta posición social de los implicados y de las importantes funciones políticas y diplomáticas del esposo abandonado. José Joaquín Godoy Cruz (1840-1901), abogado y diplomático,

6 Esta sentencia fue pronunciada el 15 de octubre de 1889 y a través de ella se otorga el divorcio perpetuo a las partes.

7 Hemos abordado estas estrategias de manejo y administración del escándalo en los artículos insertos en el dossier "Administrando el escándalo: honor y reputación en Chile, 18401920". (Undurraga: 2018; Cerón: 2018; Bergot: 2018). 
fue Encargado de Negocios en Perú y Ministro Plenipotenciario de Chile en Perú, Washington y Ecuador, entre muchos otros cargos de alto nivel que desempeñó a lo largo de su trayectoria. Durante su ejercicio diplomático en Perú jugó un papel determinante en develar el tratado de alianza entre este país y Bolivia, debiendo notificar al gobierno peruano del general Mariano Ignacio Prado la ruptura de las relaciones diplomáticas, dando inicio a la así llamada "Guerra del Pacífico" (1879-1883). Ejerció, además, el cargo de Fiscal de la Corte de Apelaciones de Santiago y ocupó la posición de Ministro de Relaciones Exteriores durante los primeros meses del gobierno de José Manuel Balmaceda. Luego de la derrota del bando balmacedista en la Guerra Civil de 1891, Joaquín Godoy permaneció algunos años en el extranjero y en 1897 fue proclamado candidato para diputado de Santiago por el Partido LiberalDemocrático (Figueroa, 1897: 50-51; Figueroa, 1929: 326-327).

Fue solo siete meses después de haber renunciado al cargo de Ministro de Relaciones Exteriores, en noviembre de 1886, que su esposa Mariana Prevost salió con escándalo de la casa que compartían, luego de un contencioso proceso de disputa matrimonial que hemos referido en las citas anteriores y que desarrollaremos a lo largo de este artículo. La connotada vida pública de Godoy fue alterada por su turbulenta intimidad, la que sería conocida, comentada y "vociferada" tanto en círculos de la elite -"en los salones i en el club"-, como en los espacios de sociabilidad de los sirvientes (Godoy, 1888: 10, 62). Según Godoy, las acciones de su esposa perseguían "de manera que es evidente, de la más completa evidencia, [...] provocar un escándalo público, que difamase a su marido en el más alto grado. En efecto, lo consiguió" (Godoy, 1888: 8). Godoy habría sido "arrastrado" por su esposa "a la condición de reo ante la sociedad i los tribunales" (Godoy, 1888: 61).

Pese a la notable coincidencia entre su salida del gabinete del presidente Balmaceda y su escandaloso divorcio, la vida pública y privada de Joaquín Godoy han sido comprendidas, hasta el momento, como experiencias divididas en estancos separados. Si bien durante los primeros diez años de matrimonio la violencia ejercida sobre su esposa no perjudicó su carrera política y diplomática, pese a que los maltratos eran conocidos por diversas figuras influyentes de las cuales dependía su cargo, una vez asentado en Chile su escandaloso divorcio afectó gravemente su reputación y tuvo repercusiones en su carrera. ${ }^{8}$

8 Coincidimos parcialmente con María Paz Fernández en cuanto a la condescendencia y tolerancia a la violencia masculina cuando esta lograba ser contenida en la esfera privada, sin afectar la carrera profesional del marido. Ciertamente, esta es la perspectiva que se colige de la lectura de la sentencia del juicio de divorcio Godoy-Prevost, a la que la autora tuvo acceso a través del texto de Ricardo Piwonka. Sin embargo, si complementamos este documento con el escrito del propio Joaquín Godoy, su "Alegato de Bien Probado", comprobamos que los escándalos domésticos efectivamente podían afectar gravemente el honor masculino y la trayectoria pública de los involucrados. (Fernández, 2011: 45-48). 
Ello nos lleva a preguntarnos en torno a las circunstancias que produjeron este cambio. ¿Cómo se explica que, en el marco de los dos años de residencia del matrimonio Godoy-Prevost en Santiago, haya estallado un escándalo de tales proporciones que involucrara a los personajes más connotados de la élite chilena -políticos, diplomáticos, sujetos adinerados, incluyendo un arzobispo-, si en el decenio anterior la sevicia que sufría su esposa no tuvo mayores repercusiones, pese a ser conocida?

Es justamente en el centro de estos cuestionamientos donde la noción "escándalo" se presenta como una interesante herramienta analítica para dar respuesta a estas preguntas. Desde nuestra perspectiva, las representaciones culturales de las prácticas escandalosas eran más amplias que las nociones jurídicas relacionadas con este concepto. La tradición jurídica castellana, que pervivió en Chile hasta la promulgación del Código Civil, el Código Penal y las leyes específicas durante el siglo XIX, vinculaba los escándalos con transgresiones sexuales y morales, tales como las blasfemias, las palabras y acciones obscenas, la vida licenciosa y las ofensas a los sacerdotes (Escriche, 1891: 638). El Código Penal chileno, aprobado en 1874, circunscribía los "hechos de grave escándalo o trascendencia" a aquellos que implicaban "ultrajes públicos a las buenas costumbres" o al pudor, consignando, a su vez, que el escándalo constituía un agravante en los casos de infidelidad masculina (Código Penal, 1884, artículos 373, 374, 381).

A la luz de la literatura sobre el tema, proponemos comprender los escándalos como formas de control social ejercidas por la opinión pública contra los responsables de comportamientos considerados impropios, así como momentos "disruptivos" e "instituyentes" que alterarían representaciones y prácticas relativas a los modelos conductuales (Jiménez, 1994: 7-36; De Blic y Lemieux, 2005: 9-38; Marcus, 2009). Del modo que la sociología contemporánea ha analizado, el escándalo no surge solo del hecho transgresivo en sí mismo, sino de su representación como suceso escandaloso por una sociedad que actuaba activamente en su construcción (Schillagi, 2011: 245-266). En efecto, no comprendemos esta noción como una existencia axiomática, inamovible y conclusiva, sino más bien como una práctica que se hallaba inserta en dinámicas sociales que contribuían a su edificación.

Las transacciones cotidianas entre el sistema de condicionamientos socioculturales y las dimensiones implicadas en la acción presente, abordadas por Pierre Bourdieu mediante los conceptos "habitus" y "campo", pueden ayudar a iluminar estas dinámicas (Bourdieu, 1991). Al concebir el "habitus" como una predisposición abierta, Bourdieu ha planteado la necesidad de incorporar el juego social. Allí es cuando la noción de "campo" introduce factores tales como las trayectorias individuales de los participantes y las propiedades de los 
grupos e instituciones envueltos en él, en un diálogo generador de prácticas (Devillard, 1995: 231-237).

De un modo semejante, los sujetos de fines del siglo XIX chileno, en este caso las mujeres de elite encarnadas en Mariana Prevost, tenían incorporado un "sentido de orientación" que les permitía conocer las reglas del juego, tales como la interacción entre rumores, escritos e impresos en la construcción del escándalo. A esa base, desde su posición relativa en relación a los otros intervinientes, cada uno de los sujetos añadía sus intereses, demandas y expectativas. Ahí comenzaba el juego, dinámica creativa y fecunda que ponía en relación las representaciones y los intereses particulares de los actores finiseculares, generando usos sociales del escándalo. A lo largo de estas páginas, observaremos cómo los escándalos podían ser construidos, controlados, magnificados y, en fin, administrados, mediante un conjunto de estrategias individuales, familiares y/o de grupo.

\section{"Un acomodo tranquilo": honor y mecanismos de control del escándalo}

Resulta evidente que no todas las transgresiones se transformaban en escándalos. En diversas ocasiones estas se manejaban, controlaban y sancionaban al interior del grupo, en particular dentro de la o las familias involucradas. Este postulado conlleva una primera dificultad, que radica en una definición de lo que era la "familia" para el siglo XIX, ya que se trataba de una entidad demográfica que unía individuos, no solo a través de los lazos sanguíneos, sino también por su pertenencia a la "domus", es decir, al espacio físico de la casa. En este sentido, el modelo familiar de elite integraba individuos con lazos sanguíneos más allá del segundo grado y el personal de servicio, siendo un "grupo doméstico complejo" (Hagerman, 1978), aunque no era un modelo aplicable a todos los estratos sociales (Cavieres y Salinas, 1991).

Dentro del mismo grupo familiar, existía un segundo nivel de contención del posible escándalo relacionado con el grupo familiar unido con lazos de parentesco. En este sentido, la correspondencia se perfilaba como una forma de control sobre los miembros de la familia, que se ejercía desde las generaciones mayores -padres hacia los hijos- o de los eclesiásticos, aplicándose en particular en asuntos que podían afectar la reputación de un individuo y, por extensión, del grupo familiar entero por compartir un apellido, marcando sin embargo diferencias entre los géneros (Castillo y Sierra, 2014a; Castillo y Sierra, 2014b; Bergot, 2013). También existían acuerdos familiares con el fin de evitar la socialización de conductas transgresoras, susceptibles de transformarse en escándalos, como el "tribunal familiar" que determinó el enclaustramiento de la escritora Teresa Wilms Montt en el convento de la 
Preciosa Sangre, en 1915, luego de conocerse su relación clandestina con un primo de su esposo.

El contencioso divorcio entre Joaquín Godoy Cruz y Mariana Prevost Moreira nos permite conocer otro mecanismo de contención, en la esfera familiar, de un eventual escándalo. En efecto, meses antes de la sonada huida de Mariana, se había venido fraguando un "arreglo privado" mediante el cual se buscaba solucionar las desavenencias y los conflictos de pareja al interior de la red familiar. Se trataba de la intervención mediadora de familiares y amigos -todos hombres-, que pretendía, según palabras de Joaquín Godoy, "arribar a un acomodo tranquilo", un "arreglo amistoso", un "modus vivendi", que permitiera mantener la apariencia del matrimonio, evitando la deshonra familiar (Godoy, 1888: 7, 68).

Las negociaciones para este acuerdo habrían sido desechadas por Mariana Prevost en marzo de 1887, solo tres meses antes de su huida del hogar y cuatro meses después de la renuncia de Domingo Godoy a su cargo de Ministerio de Relaciones Exteriores. Resulta interesante observar que, desde la perspectiva masculina, evidenciada a través del escrito de Godoy, las tentativas conciliadoras atañerían a agentes masculinos, en tanto que las acciones disruptivas de la paz y tranquilidad familiar se vincularían a acciones femeninas. Los hombres serían, desde el discurso masculino, los agentes del orden, en tanto que la mujer el eje del desorden y la protagonista del escándalo, como detallaremos en las páginas siguientes.

La lógica argumentativa del "Alegato de Bien Probado" de Joaquín Godoy instalaba al marido como garante de la estabilidad, quien, con "austera resignación", "reserva", "caudal de ilimitada paciencia" y "condescendencia inagotable", encarnaría la sensatez ante la cólera y arrebato femeninos (Godoy, 1888: 8, 75). El referente conductual del hombre prudente y paciente, que dirigía sus acciones según los parámetros de la razón, correspondía a un modelo ligado a una de las representaciones de honor cercanas a la retórica y a las prácticas de civilidad (Undurraga, 2012: 219-256). Ciñendo su conducta de acuerdo a este modelo, Godoy podía establecer contrastes dicotómicos respecto al proceder de su esposa. Así, por ejemplo, indicaba que:

"Yo jamás he desplegado mis labios para hacer revelaciones de ningún jénero, ni aun en el seno de la mayor intimidad, al paso que esa señora me ha perseguido con lo que ella misma califica en sus absoluciones de posiciones de confidencias, que no han sido otra cosa que el corrosivo de mi reputación i de mi dignidad de hombre. El marido es el último en apercibirse de esta obra de zapa de su personalidad social" (Godoy, 1888: 12, 13). 
Era justamente aquella "personalidad social", a la que se refería Joaquín Godoy, la que se entendía en plano de sinonimia con el "honor" en el contexto histórico estudiado. La historiografía latinoamericana de los últimos quince años ha consensuado que la transición de la sociedad colonial al siglo XIX, y luego al XX, no implicó el ocaso del honor sino la reconfiguración de sus significaciones y la reestructuración de sus adscripciones sociales. Durante el periodo republicano este fue relevante en los procesos de construcción de la modernidad -la esfera pública, la ciudadanía y el Estado-, así como en la definición de las identidades sociales en distintas regiones del continente. Así, Caulfield ha subrayado que el honor-y en particular el honor sexual- era "un problema de preocupación inmediato y objeto de debate acalorado" para la mayoría de los habitantes de Río de Janeiro entre 1920 y 1945, aunque no existía consenso sobre su significación. Durante esas décadas, las interacciones entre honor, estatus, ciudadanía, patriarcado y ley fueron relevantes en los procesos de construcción de la modernidad en Latinoamérica (Caulfield, 2000: 3; Caulfield, Chambers y Putnam, 2005).

Ahora bien, ¿cómo era posible el menoscabo del honor de un sujeto de elite, para quien la honra formaba parte de su capital heredado por su misma pertenencia a ese sector social? Asimismo, ¿cómo puede entenderse aquella destrucción de "la personalidad social" de un hombre público, con alto desempeño en la política y la diplomacia del país, producto de acusaciones de malos tratos en un contexto en que la "corrección" de la conducta femenina era un derecho del esposo? El uso político del escándalo familiar no pasó desapercibido para Joaquín Godoy. En efecto, él mismo preguntaba si "habrá algo que produzca el más alto grado que esas acusaciones el desprestigio i el deshonor de un hombre que, a la vez de ser persona privada, de honrada posición social, ha ocupado expectables puestos públicos" (Godoy, 1888: 98).

La respuesta a la primera interrogante debe considerar el uso estratégico por parte de Joaquín Godoy de las causales de divorcio según la Ley de Matrimonio Civil, promulgada el 16 de enero de 1884. En efecto, la línea argumentativa, desde la que se adjudicaba a Mariana Prevost el haber orquestado un "sistema de inexorable" o "cruel difamación" destinado a menoscabar el honor de su esposo, se entendía en el contexto de la tercera causal del artículo 21 de dicha ley, por la que el divorcio procedía por "ser uno de los cónyuges autor, instigador o cómplice en la perpetración o preparación de un delito contra los bienes, la honra o la vida del otro cónyuge" (Godoy, 1888: 61; Piwonka, 1929: 30; Ley de Matrimonio Civil, 1884, artículo 21, causal 3). Es decir, la retórica del deshonor invocada por Godoy, y vinculada a las acciones de su esposa, buscaba obtener el divorcio según una causal imputada a las transgresiones de Mariana Prevost. Con ello, a la vez, el esposo podría eventualmente eclipsar los graves cargos que esta acusaba, relativos 
a los "malos tratamientos graves i repetidos, de obra o de palabra" (Ley de Matrimonio Civil, 1884, artículo 21, causal 2; Piwonka, 1929: 30).

El marido imputado hacía referencia explícita a la causal de la difamación del cónyuge, en este caso, él mismo, al señalar: "¿no será delito de esa especie el propalar en todas partes, en diversos países, por medio del anónimo, del chisme de la confidencia insidiosa, de la cooperación de la servidumbre, etcétera, que el marido es un ebrio consuetudinario, que es un avaro despreciable, que es un verdugo de su familia, que es el atormentador diario de la mujer por las palabras i por el hecho?" (Godoy, 1888: 98).

Godoy elaboró una retórica de la victimización en cuanto esposo difamado e irremediablemente dañado en su reputación. Así, Mariana Prevost habría "tratado de perderme en el concepto público, hasta concitarme el odio de infinidad de gentes" (Godoy, 1888: 62). Producto de ello, se habría creado a su alrededor una "atmósfera de desprestijio", ya que su esposa "ha saturado de tal manera la atmósfera de mi patria [con] su ponzoñosa influencia" (Godoy, 1888: 39, 97). Para destacar aún más su vejación y el éxito Prevost en tal cometido, Godoy señalaba que incluso había llegado a ser "de buen tono en esta ciudad despedazar mi honra", instalando en el espacio urbano una serie de dinámicas de menoscabo del honor a través del rumor, nutridas, a la vez, por la circulación de escritos difamatorios (Godoy, 1888: 59).

El hecho de que el honor se viera menoscabado por una falta moral o una violación a las normas sociales, se explicaba por su progresiva asimilación a una reputación modélica. El capital heredado -el linaje y la legitimidad-continuó siendo importante en la concepción elitaria del honor; sin embargo, en el tránsito del siglo XVIII al XIX, el juicio de los pares asumió un papel cada vez más relevante en la definición de un honor asimilado al comportamiento virtuoso (Undurraga, 2012). La frase "el honor no es más que la buena opinión" -enunciada en un juicio por injurias en Chile en 1822 (Undurraga, 2005) - evidenciaba una realidad constatada asimismo en diversos espacios americanos durante el siglo XIX, como Buenos Aires (Gayol, 2000), Ciudad de México (Teitelbaum, 2008), Arequipa (Chambers, 1999) y Lima, a través de los imaginarios sobre la "gente decente" (Whipple, 2013). La relevancia de la buena conducta -ratificada socialmente- en la conformación de un honor-reputación ponía en evidencia su naturaleza negociable (Undurraga, 2014; Piccato, 2010; Gayol, 2008; Johnson y Lipsett-Rivera, 1998; Langue, 1995). Tanto en esta como en publicaciones anteriores, hemos demostrado que durante el siglo XIX se acentuó la fragilidad del honor-reputación, lo que repercutió en la proliferación de escándalos y sus formas de administrarlos (Undurraga, 2018).

Al trascender el escándalo, dañando el honor de los involucrados, estos no se resignaban a constatar su descrédito. Por el contrario, estos actores 
participaban activamente de la discusión, administrando el escándalo por medio de la palabra escrita que circulaba entre el público a través de diversos medios. La importancia del escrito -en particular, del impreso- en la defensa del honor y la reputación durante los siglos XIX y XX no fue un fenómeno exclusivo del contexto chileno, sino que una práctica constatada para otros espacios latinoamericanos. En este sentido, Piccato $(2010,2004)$ ha comprobado que el honor masculino, un bien legal protegido por el Estado, fue el cimiento de la esfera pública mexicana en el cambio de siglo. El honor no habría sido un agente anti-racional sino, junto a la reputación y al uso público de la palabra, fue determinante en la conformación del México moderno (Picatto, 1999 y 2010).

Por su parte, en la Argentina de fines del siglo XIX y de las primeras décadas del siglo XX, las elites políticas e intelectuales también reflexionaron por escrito -en ensayos, artículos de prensa, tesis y manuales de Derecho- sobre el "honor moderno" (Gayol, 2004). Entendieron este concepto -asimilado a la probidad, la virtud y la honestidad-como un orden moral universal que debía guiar a toda la sociedad, denunciando paralelamente la existencia de "falsos honores" (Gayol, 2008). A su vez, al precisar los contornos de la opinión pública ante la cual el honor debía defenderse, la identificaron con la de aquellos hombres honorables y moralmente equivalentes, lo que en la práctica equivalía a los pares sociales (Gayol, 2004).

En estas discusiones en torno a los "verdaderos" significados del honor, los intelectuales subrayaron el valor de la cultura escrita (Chartier, 2000) en la defensa de la reputación, en desmedro de la violencia que continuaba siendo la vía privilegiada por los plebeyos para restaurar la suya. Ahora bien, a las riñas plebeyas que expresaban emociones desbordadas, pasiones destructivas y conductas instintivas, se oponía el duelo elitario, comprendido como "violencia elegante" y práctica promotora de civilidad (Gayol, 2008; Piccato, 1999). Sin desconocer que los hombres de la elite chilena pudieron usar el duelo para defender su honor, nuestras investigaciones nos permiten postular que el uso del escrito fue la vía privilegiada por estos y los actores de los grupos medios para alcanzar dicho propósito (Undurraga, 2018). Como constataremos a lo largo de estas páginas, la administración de los escándalos en Chile involucraba primordialmente tanto mecanismos de control parental y familiar, como el uso de la palabra, del impreso y de la justicia.

\section{"Chismes de cocina". Redes domésticas en la construcción del escándalo}

"En esta sociedad se había corrido que en Washington tenía yo a la señora Prevost casi desnuda y padeciendo de hambre; que aquí en 
Chile se comía en mi casa peor que en un café chino; i que mi familia apenas tenía con que cubrir sus cuerpos. Todo este tejido de groseras falsedades, con las cuales se ha fraguado una horripilante leyenda para el uso de todos los chismosos, los envidiosos i los malquerientes, ha venido por tierra sin que la demandante haya podido presentar otro testimonio en su apoyo que el de una señora, que dice que un día le mandó una gallina de regalo" (Godoy, 1888: 11).

Nos preguntábamos anteriormente sobre las posibilidades de deshonra y descrédito de un hombre de elite a partir del conocimiento público de los maltratos que infería a su esposa, en un contexto en que la "corrección" de la conducta femenina era un derecho del marido. Sin duda que la defensa masculina del orden patriarcal incluía "la subordinación de la mujer al marido [la que] comprendía el derecho a corrección y, como corolario, el castigo" (Rengifo, 2011: 173). Se ha demostrado que la violencia era un fenómeno extendido en la sociedad chilena tradicional y, en particular, en los espacios domésticos (Fernandez, 2011; Rengifo, 2011; Salinas, 2008: 9-22; Salinas, 2000: 13-49; Salinas y Goicovich, 1997: 237-268). En este sentido, el caso de Mariana Prevost no resulta particularmente excepcional. Lo que le otorga excepcionalidad es justamente que la socialización de estas prácticas de violencia afectara el honor y el desempeño político de Joaquín Godoy. Este es el punto en que nos encontramos con la construcción del escándalo y las formas de administrarlo.

Si bien la gravedad de la sevicia -o excesiva crueldad en los malos tratospudo incidir en el descrédito del esposo, resulta esencial incorporar al análisis los mecanismos de elaboración del escándalo en el contexto estudiado, con el fin de comprender cabalmente esta situación. No es coincidencia que los costos políticos y sociales del maltrato ejercido por Godoy se produjeran cuando el matrimonio se encontraba viviendo en Chile y no durante sus estancias en el extranjero. Si bien la sevicia se ejerció en todos los periodos de su vida marital, e incluso llegó a oídos del propio Arzobispo Casanova durante su estancia en Washington, Joaquín Godoy no cayó en el desprestigio público ni fue removido de sus funciones político-diplomáticas. ${ }^{9}$ Esto último solo sobrevino al asentarse en su país y en la medida que su esposa fue capaz de construir redes que le permitieron elaborar un escándalo de proporciones, el que también la facultó para poner fin a su matrimonio y a las situaciones de violencia que vivía en él.

9 En este punto, concordamos con María Paz Fernández respecto al desempeño de Joaquín Godoy durante su estadía en Washington. Sin embargo, si seguimos su trayectoria durante los años siguientes, y a la luz de los documentos exhibidos en este trabajo, resultan evidentes los perjuicios que debió enfrentar al verse involucrado en el escándalo de su bullado divorcio (Fernández, 2011: 45-48). 
La demanda por divorcio perpetuo entablada por Mariana Prevost contra su marido Joaquín Godoy se basó en lo dispuesto en el artículo 21, números 2 y 5 de la Ley de Matrimonio Civil de 1884. Como ilustra la cita con la que abrimos este apartado, junto a la invocación de la sevicia reiterada, Mariana también fundó su denuncia en la "avaricia del marido, si llega hasta privar a su mujer de lo necesario para la vida, atendidas sus facultades" (Piwonka, 1929: 30; Ley de Matrimonio Civil, 1884, artículo 21, causal 5). La documentación nos indica que la demanda de Prevost hacía referencia a las "impertinencias gravísimas" que recibía de su marido durante su estancia en Lima; que luego, en Quito y Washington, fue objeto de "verdadera sevicia" incluso conocida por el público y la prensa, y que, en Chile, este maltrato llegó a "hacérsele insoportable" (Godoy, 1888: 10).

Indicó, asimismo, que el último episodio violento lo vivió la noche anterior a su huida del hogar. Que, en esa ocasión, luego de una cena ofrecida en su casa, Godoy habría destrozado un servicio de porcelana, luego de lo cual la habría insultado y "se lanzó sobre ella a puñetazos i patadas, persiguiendola así hasta la pieza de la cocina, donde hubo de refujiarse, i de allí, con grande escándalo de sus hijos i sirvientes, la saco obligándola a arrodillarse, humillandola i diciéndole que era culpable de difamación contra el. Que la escupió delante de los criados, i como implorase por ella la niña mayor, la amenazó con golpearla i aun matarla" (Piwonka, 1929: 29; Godoy, 1888: 10).

Más allá de los episodios puntuales de violencia, lo que aquí nos interesa es conocer los mecanismos a través de los cuales los sujetos involucrados intentaron elaborar o evitar, construir o controlar y, luego, administrar en beneficio propio las repercusiones del conocimiento público de estas situaciones de maltrato. Hemos mencionado que la agencia femenina y la construcción de redes de apoyo fueron esenciales en la elaboración del escándalo que prestó las condiciones de posibilidad para la huida del hogar por la mujer maltratada. Estos hechos, luego, permitirían al esposo solicitar el divorcio perpetuo, en respuesta a la demanda de Mariana Prevost, por causas enteramente imputadas a esta última (Piwonka, 1929: 30).

Un primer ámbito de acción femenina se planteaba en el marco del espacio doméstico, el que se transformaba en un contexto en disputa por las lealtades de sus integrantes. Así, una de las acciones más efectivas realizadas por Mariana Prevost fue contar con el apoyo y la complicidad de la mayoría de sus sirvientes. Estas, pues se trataba de mujeres, no solo fueron testigos de Prevost en el juicio de divorcio, fundamentando la sevicia y la avaricia de las que era objeto, sino también, y de manera fundamental, actuaron como agentes del rumor en la construcción del escándalo (Bergot, 2017: 11-41; Bergot, 2018; Salinas, 2000: 133-154). El papel de los domésticos como articuladores de los espacios privado y público, en cuanto piezas importantes de la imagen que las elites proyectaban, ha sido analizado para diversos 
espacios durante el periodo estudiado, incluido el chileno (Bergot, 2018; Fernández, 2014: 127-142).

Así, por ejemplo, las sirvientas iban de madrugada a las casas de las amigas de Mariana "a pedirle auxilio para su ama", entregaban las cartas anónimas que ésta redactaba y hacían circular los rumores sobre las vejaciones que Prevost recibía de parte de su esposo (Godoy, 1888: 22). Estos comentarios circulaban entre los sirvientes de otras casas de elite y, a través de éstos, llegaban a los amos (Godoy, 1888: 37, 89). Pero también existía un flujo directo entre los criados de Mariana y los sujetos de elite, quienes, en ocasiones, recibían la visita de los primeros, los que, con diversas excusas, aprovechaban de divulgar la apremiante situación en la que se hallaba su ama. Esto último se expresó, por ejemplo, en la declaración que prestó el expresidente Domingo Santa María en el juicio de divorcio Godoy-Prevost, señalando que una de las sirvientes de Mariana se presentó en su casa solicitándole una entrevista para su ama y "si bien quiso [la criada] instruirlo de lo que pasaba en casa de su señora, el le impuso silencio i la hizo retirarse" (Godoy, 1888: $58,76)$. La imposición de silencio a la criada no solo daba cuenta, dentro del "Alegato" de Godoy, de la procedencia social de Santa María, sino también de la autoridad masculina como garante del orden familiar amenazado por los rumores femeninos.

Los rumores, asimismo, se divulgaban a través de la circulación, como empleados, de los sirvientes por las distintas casas de elite. Nos consta, por ejemplo, que una de las criadas más cercanas a Mariana Prevost, la cocinera María de la Luz Valenzuela, también lo había sido antes en la casa de Domingo Santa María (Godoy, 1888: 69). Y, luego de salir de la casa de Godoy, fue empleada por las señoras Josefa de la Fuente de Nissen y Carolina Nissen de Beauchef, quienes también fueron testigos en el juicio de divorcio. Pese a ello, y con el fin de distanciarse del escándalo que consumía a la sociedad santiaguina del momento, estas últimas señalaron "que no prestaban juramento ni ninguna declaración, porque nada sabían de estos asuntos, tanto que no conocían ni de vista ni a Don Joaquín Godoy ni a doña Mariana Prevost, agregando la señora Carolina Nissen de B. que, si algo tuviera que declarar por lo que ha oído, su declaración sería en contra del señor Godoy" (Godoy, 1888: 84). Con ello, pese a no conocer personalmente a los involucrados, la mujer evidenciaba la profusa circulación de rumores en torno al caso y el consiguiente descrédito de Joaquín Godoy.

Ciertamente, Godoy intentó desacreditar los testimonios de las sirvientas, a las que consignó como mujeres "del bajo pueblo" (Godoy, 1888: 19). Asimismo, descalificaba los mecanismos mediante los cuales su esposa logró dar a conocer los maltratos de los que era objeto, ironizando el recurso a los criados como agentes de socialización. Objetivaba su desprecio en el espacio doméstico por excelencia de los sirvientes, a saber, la cocina. Así, por 
ejemplo, consignaba satíricamente aquellas prácticas de "difamación en la cocina en asamblea con los sirvientes" y calificaba los rumores en torno a su persona como "chismes de cocina, a los que nadie presta crédito" (Godoy, 1888: 13, 31).

Ahora bien, en la construcción de este escándalo no solo intervinieron los rumores, sino que, asimismo, se observaron nutridas y permanentes interacciones entre oralidad y escritura. En efecto, junto con la promoción de rumores que recorrían los corrillos y los salones -es decir, espacios populares y elitarios de la ciudad de Santiago-, Mariana Prevost también optó por la palabra escrita para difundir la sevicia y, en particular, las carencias materiales que experimentaba. Para ello, recurrió a la redacción de anónimos que, a través de sus sirvientes o del correo urbano, dirigía a los sujetos de elite, lo que se verificó durante el primer semestre de 1887, es decir, en los meses que precedieron a la salida de Prevost del hogar que compartía con Godoy, en julio de ese año (Godoy, 1888: 55). Los pormenores de la historia del matrimonio Godoy-Prevost incluso llegaron a la prensa y, por cierto, fueron socializados a través de impresos, como nos consta a partir de la publicación del "Alegato de Bien Probado" que Joaquín Godoy hizo circular en la sociedad de su tiempo. ${ }^{10}$

La interacción entre los mecanismos tradicionales -el rumor-y los modernos -a saber, el impreso y la prensa-, constituye uno de los aspectos más interesantes del escándalo que nos concierne. De este modo, nos es posible comprender tanto la relevancia de la escritura como motor de cambio sicológico, social, político y económico, así como los diálogos permanentes entre esta y una serie de prácticas de oralidad de enorme riqueza (Ong, 2006; Goody, 1993 y 1996; Olson y Torrance, 1991). En el contexto de una "ciudad letrada" -una sociedad basada en la primacía de la palabra escrita-, la oralidad presentaba múltiples formas de significar lo escrito y sus receptores desempeñaban un papel relevante (Rama, 1984). En efecto, las "comunidades de lectores" (Chartier, 1994) definían formas específicas de apropiación, significación y traducción (Burke y Po-Chia, 2010). Ahora bien, tanto los mecanismos femeninos -rumores y anónimos-como los masculinos -impresos- de administración del escándalo apelaban a receptores específicos de sus discursos, a saber, la elite de Santiago de Chile.

Magnificando la situación, y dando cuenta de la notable interacción entre rumores y escritos anónimos, así como del espacio social de circulación de estos, Joaquín Godoy indicaba en su "Alegato de Bien Probado" que "quizá no hai en Santiago persona decente que no haya recibido, o al

10 La publicación en la prensa de los malos tratos que Godoy infería a Prevost consta tanto en el "Alegato de Bien Probado" como en la sentencia de divorcio (Piwonka, 1929: 29, 33). 
menos oído que algunos de sus amigos han recibido anónimos en mi contra" (Godoy, 1888: 58). Caracterizaba los anónimos que su esposa escribía como "libelos repugnantes", instalando esta práctica en el ámbito criminal, toda vez que estas expresiones, al ser escritas, recibían mayor penalidad que las ofensas verbales (Godoy, 1888: 71; Código Penal, 1884, artículo 418). En concordancia con ello, la sentencia de divorcio perpetuo, dictada en marzo de 1889, consignaba que Don Juan Rivadavia, Don Fidelis del Solar, Doña Mariana del Rosario Vergara y Don Eulogio Altamirano habían "recibido anónimos calumniosos y ofensivos para Don Joaquín Godoy" (Piwonka, 1929: 35).

El daño a la reputación de Godoy fue especialmente gravoso a partir de la circulación de anónimos. Ello explica que éste haya atribuido particular importancia a estos hechos y a las acusaciones vertidas a través de ellos. Las imputaciones que Godoy más resentía eran aquellas relacionadas con la quinta causal de la Ley de Matrimonio Civil de 1884, referidas a la avaricia del marido (Piwonka, 1929: 30; Ley de Matrimonio Civil, 1884: artículo 21, causal 5). Así se lamentaba en el cierre de su "Alegato de Bien Probado", indicando que "la supuesta desnudez de esa señora ha sido uno de los puntos de partida más capitales de la propaganda difamatoria que emprendió i que todavía sostiene contra mí" (Godoy, 1888: 108).

El uso femenino de la escritura desempeñó un papel relevante en la intervención de las mujeres en el espacio público a lo largo del siglo XIX y, fundamentalmente, durante las primeras décadas del siglo XX (Amaro, 2012: 15-28; Doll, 2007: 83-100; Kottow, 2013: 151-169; Traverso, 2012: 61-80; Montero, 2018; Batticuore, 2005). En este caso, Mariana Prevost erigió esta práctica como uno de los principales pilares para construir el escándalo que le permitiría, unos meses más tarde, justificar su abandono del hogar ante la sociedad del momento y promover su divorcio a solo pocos años de ser promulgada la Ley de Matrimonio Civil que lo facultaba.

\section{Emociones femeninas y redes de apoyo como sustento del escándalo}

Mariana Prevost, junto a sus hijos y su esposo, se habría instalado en Chile durante el año 1885, luego de que este último cumpliera con diversas destinaciones diplomáticas a las que había sido asignado en el extranjero (P. Figueroa, 1897: 50). ${ }^{11}$ Este dato resulta relevante si consideramos que 11 Se trataría, en este caso, de la renuncia que Godoy hiciera al cargo de Ministro Plenipoten-
ciario de Chile en Estados Unidos (Godoy, 1888: 41). 
Mariana, de origen peruano, contó con cerca de dos años para forjar las redes de apoyo que posteriormente le darían el sustento material y social para divorciarse de su esposo, un hombre totalmente inserto en el contexto político y social del Santiago de Chile del periodo.

Durante esos años, Mariana frecuentó los espacios de sociabilidad de la elite y comenzó a compartir confidencias con un círculo de amigas. Por ejemplo, doña Matilde Simpson de Goñi, vecina de Mariana Prevost, declaró en el juicio que "la ha oído [a Prevost] quejarse i llorar amargamente" (Godoy, 1888: 38, 39). Evidentemente, desde la perspectiva de Godoy, su esposa ejercía de manera sublime el rol de "víctima", mostrándose siempre "pobre i necesitada, para excitar la compasión", "haciéndose aparecer casi pobre de solemnidad", lo que se habría visto favorecido por su condición de extranjera (Godoy, 1888: 5, 12, 35, 60). En la práctica, Mariana Prevost habría hecho uso de una racionalidad específica en sus comportamientos (Levi, 1990: 11, 12). Sus estrategias de acomodación y manejo del mundo social le permitieron construir lazos con una serie de sujetos -sirvientes, vecinas, mujeres de elite $y$, a través de ellas, sus maridos, junto con los cuatro médicos que la asistían-, quienes luego operarían como una red de apoyo que le permitiría abandonar a su esposo y luego obtener el divorcio perpetuo. ${ }^{12}$

Para conseguir esos propósitos, Prevost no sólo se conformó con difundir comentarios sobre los malos tratamientos que recibía y las carencias materiales que debía soportar con sus hijos. Junto a ello, desarrolló una serie de prácticas para visibilizar, aún más, en su contexto social, la precaria situación en la que se encontraba. Con ello, jugaba y utilizaba hábilmente la quinta causal de la Ley de Matrimonio Civil de 1884 que, como hemos mencionado, se refería a la avaricia del marido (Ley de Matrimonio Civil, 1884, artículo 21, causal 5; Piwonka, 1929: 30). Así, por ejemplo, empeñó parte de su vestuario, todas sus joyas y objetos de uso personal, solicitó ropa y zapatos para sus hijos e incluso pidió dinero prestado y también alimentos en el vecindario (Godoy, 1888: 62, 91; Piwonka, 1929: 30).

Desde el punto de vista de Joaquín Godoy, todas estas prácticas habrían tenido el único objetivo de difamarlo y correspondían a "comedias", farsas y puestas en escena que no se correspondían con la holgada realidad económica que se disfrutaba en su casa. Por ejemplo, este indicó que su esposa habría llegado a esconder y mantener "ocultas las ropas que en copiosa cantidad

12 Se trata de "los facultativos señores Moericke, Agustín Gana, José Joaquín Aguirre i Vicente Izquierdo", quienes prestaron asistencia médica a Mariana Prevost después de su fuga del hogar, cuando estuvo internada en el Hospital San Borja. A su vez, estos emitieron un informe sobre el estado de salud de Mariana y también prestaron testimonio en el juicio de divorcio (Piwonka, 1929: 32). 
poseía i de las que aún existe tanta como para asombrar a los que han oído la calumnia", al mismo tiempo que las solicitaba para ella y sus hijos (Godoy, 1888: 91). Por cierto, también indicó no haberse apercibido de la ejecución de estas acciones en el momento, sino después del abandono del hogar consumado por su esposa.

La sentencia de divorcio validaba en parte la perspectiva de Godoy, al dictaminar que solo concurría la segunda causal del artículo 21, que consagra la sevicia, no así la causal quinta, referida a la avaricia del marido. Así, en esta se indicaba que "Don Joaquín Godoy mantenía su casa en el pie de decencia i bienestar correspondiente al rango i posición social de ambos cónyuges, participando a su esposa de las comodidades necesarias a la vida" (Piwonka, 1929: 34). Ello se había demostrado tanto a través de las declaraciones de testigos como por medio de "recibos corrientes" presentados al tribunal (Piwonka, 1929: 34).

La necesidad de apoyo para concretar la emancipación del esposo quedó en evidencia, una vez más, en los sucesos que formaron parte de la huida del hogar aquella madrugada de julio de 1887, cuando Mariana Prevost se presentó con una de sus hijas en casa de dos mujeres conocidas. No se trataba solo de mujeres cercanas, sino de esposas de connotados hombres de la sociedad de su tiempo. Ellos eran el Ministro Plenipotenciario de la República Argentina, José Evaristo Uriburu, y Agustín Edwards Ross, uno de los hombres más adinerados de su tiempo y con una amplia trayectoria política que lo llevó a ser Ministro de Estado, diputado y senador de la República.

La internación de Mariana Prevost, ese mismo día en el Hospital San Borja, tampoco podía pasar desapercibida. Ella no solo había sido mediada por el Arzobispo de Santiago, Mariano Casanova y Casanova, sino que la misma estancia de la mujer en el lugar se transformó en un hecho de relevancia social. En efecto, Mariana fue visitada tanto por los cuatro médicos que emitieron el informe sobre su estado salud al tribunal, como también por varias mujeres de elite.

Ciertamente, Joaquín Godoy trató discursivamente esta práctica como una "farsa, inaudita hasta entonces en Chile, de refugiarse a una cama de un hospital público" (Godoy, 1888: 90). Ella solo podía ser producto de una mujer de "temperamento nervioso e irritable", sujeta a "arrebatos de cólera" y con tendencia a "gritar, exasperarse, armar escándalo" (Godoy, 1888: 9 , $12,47)$. Es más, a causa de "los rastros de la volubilidad, inconsistencia i falta absoluta de escrúpulos" de su esposa, Godoy indicaba que no podía "menos que llamarla desgraciada" (Godoy, 1888: 9, 12).

La representación de la mujer como eje de desorden e inestabilidad se nutría del modelo decimonónico de naturaleza femenina que postulaba la 
"desigualdad biológica de la mujer y su disposición natural a la sensibilidad, la maternidad y el sufrimiento" (Araya, 2006: 6). Este imaginario se basaba en el supuesto vínculo fisiológico entre el sistema reproductor y el sistema nervioso, que dibujaba un límite difuso "entre la fisiología y la patología femenina, es decir, entre la normalidad y la anormalidad" (Araya, 2006: 8; Sagredo, 2006: 32). La disposición "natural" de la mujer a un permanente estado nervioso radicaba en el útero, el órgano que daba origen a la histeria. Los discursos científicos y socioculturales de patologización de la mujer se vincularon a patrones emocionales específicamente femeninos que circularon en el contexto chileno de fines del siglo XIX (Undurraga, 2016).

En otro lugar hemos analizado las formas en que los hombres decimonónicos hicieron uso de una variedad de emociones, como la pasión, la tristeza, la melancolía, los celos, la ira, el odio, el hastío, la angustia, el dolor y la envidia, entre otras, para significar las acciones femeninas (Undurraga, 2016). El uso estratégico de los contextos emocionales del periodo se planteaba a partir de una evaluación previa de su factibilidad. ${ }^{13}$ Es decir, más allá de que Mariana Prevost efectivamente haya tenido un temperamento nervioso e irritable, el discurso masculino expresado en el "Alegato de Bien probado" de su esposo evidenció el uso de una matriz de comprensión de sus actuaciones en clave emocional que sería comprendida por el público lector. Más aún si dicho temperamento femenino era presentado como el origen del escándalo "i la ruina de [su] familia" (Godoy, 1888: 12).

De allí que el "Alegato de Bien Probado" de Joaquín Godoy estuviera colmado de referencias al "carácter irascible de la señora Prevost", así como a "su propensión a armar escándalos" (Godoy, 1888: 49). Para este diplomático y político chileno no parecía haber contradicción alguna entre el carácter manipulador de una mujer que era capaz de manejar su entorno con el fin de crear un enorme escándalo público y la supuesta irracionalidad y temperamento colérico y arrebatado que también habrían caracterizado a su esposa.

\section{A modo de conclusión}

A lo largo de estas páginas, y a través del contencioso divorcio entre una aristócrata limeña y un connotado político y diplomático chileno, hemos analizado las formas de administrar el escándalo en un contexto histórico

13 Por contextos emocionales entendemos las configuraciones socioculturales que significan y que, por tanto, otorgan sentido a los diversos estados conceptuados como "emociones" en un periodo y en un grupo determinado. Esta noción está en diálogo con la de "comunidades emocionales" (Rosenwein, 2006), así como con la "economía histórica de las emociones" propuesta por Ute Frevert (Frevert, 2011 y 2014). 
en el que la asimilación del honor a la reputación otorgó mayor visibilidad a este fenómeno. Hemos observado cómo en el Santiago de Chile de fines del siglo XIX las elites movilizaban un conjunto de estrategias individuales, familiares y/o de grupo con el fin de administrar el potencial escándalo como elemento dañino para la reputación. En una primera instancia, se intentaba contener en la esfera privada a través de mecanismos de control parental y familiar y, en segunda instancia, al adquirir notoriedad pública, se enfrentaba a través del uso de la palabra, del impreso y de la justicia.

Resultó interesante constatar las diferencias de género en la administración del escándalo, observándose la tendencia femenina a usar el rumor y los contactos personales, en tanto que los hombres recurrían a la opinión pública, incluso a través de la publicación de impresos. Asimismo, y desde la perspectiva del esposo, las tentativas conciliadoras atañerían a agentes masculinos, en tanto que las acciones disruptivas de la paz y tranquilidad familiar se vincularían a acciones femeninas. Los hombres serían, desde el discurso masculino, los agentes del orden, en tanto que las mujeres los ejes del desorden y las protagonistas del escándalo.

Asumiendo las fronteras porosas y las interacciones permanentes entre la esfera doméstica y la pública, nos preguntamos por las condiciones de posibilidad de la deshonra de un hombre de elite a causa de las transgresiones verificadas en su intimidad. En particular, nos interesó explicar cómo fue posible que durante los dos años de residencia del matrimonio Godoy-Prevost en Chile estallara un escándalo de proporciones que involucrara a los personajes más connotados de la elite, si en el decenio anterior la sevicia que sufría la esposa, pese a ser conocida, no tuvo mayores repercusiones. Más allá de los episodios puntuales de violencia, nos interesó conocer los mecanismos a través de los cuales los sujetos involucrados en el contencioso proceso de separación y divorcio, intentaron elaborar o evitar, construir o controlar y, luego, administrar en beneficio propio las repercusiones del conocimiento público de dichas situaciones de maltrato.

Evidenciamos los mecanismos a través de los cuales la agencia femenina y la construcción de redes de apoyo fueron esenciales en la elaboración de un escándalo que prestó las condiciones de posibilidad para la huida del hogar por la mujer maltratada. Se observó un primer ámbito de acción femenina destinado a obtener las lealtades de los integrantes en el espacio doméstico. La alianza con las sirvientas no solo resultó relevante para contar con futuros testigos en el juicio de divorcio, sino también con importantes agentes de socialización de la sevicia y las carencias materiales que la esposa debía afrontar cotidianamente.

Ahora bien, en la construcción del escándalo no solo intervinieron los rumores que difundían los criados en las casas de la elite de Santiago, sino que asimismo 
se observaron nutridas y permanentes interacciones entre oralidad y escritura. En efecto, junto con la promoción de rumores que recorrían los espacios populares y elitarios de la ciudad de Santiago, Mariana Prevost también optó por la palabra escrita para difundir el maltrato y, en particular, las privaciones que experimentaba en su convivencia marital. Para ello recurrió a la redacción de anónimos que dirigía a sujetos de elite, poniendo en evidencia el papel relevante que desempeñaba la escritura en la intervención de las mujeres en el espacio público durante los últimos decenios del siglo XIX y los primeros del siglo XX.

De este modo, las tentativas masculinas de alcanzar un "arreglo privado", a través del cual se contuvieran los conflictos de pareja y se invisibilizara el maltrato al interior de la red familiar, no lograron concretarse. Lejos de ello, la mujer involucrada logró forjar las redes de apoyo que le otorgaron el sustento material y social para divorciarse de su esposo. Por esto, los episodios protagonizados por ella y una de sus hijas aquella madrugada de julio de 1887 , cuando Mariana Prevost sale de su hogar y se dirige a dos casas de elite para luego internarse en un hospital, no pueden leerse como una anécdota propia de "novela patibularia", como su esposo quiso demostrar. Estos, más bien, deben comprenderse como una de las tantas estrategias de acomodación y manipulación del mundo social que han desplegado los sujetos históricos, evidenciando la racionalidad específica de sus comportamientos. Para esta mujer, la construcción de un escándalo que involucró a la elite chilena del momento fue una de ellas.

\section{Referencias bibliográficas}

\section{Fuentes primarias}

\section{a) Archivos}

Archivo Nacional de la Administración (ARNAD), Fondo Conservador de Bienes Raíces de Santiago, Vol. 87, fj. 28 y Vol. 94, fj. 416.

\section{b) Impresos y documentos oficiales}

Chile. (1874). Código Penal de la República. Santiago: Imprenta Nacional.

Chile. (1884). Ley de Matrimonio Civil. Diario oficial. Santiago: Imprenta Nacional.

Chile. (1889). Gaceta de los Tribunales. 1889, tomo II. № 3047. Santiago: Imprenta Nacional.

Godoy, J. (1888). Alegato de bien probado. Presentación por parte de D. Joaquin Godoy. En el juicio de divorcio perpetuo. Promovido por Da Mariana Prevost. Santiago: Imprenta "Victoria" de H. Izquierdo i Ca. 
Piwonka, R. (1929) Los Juicios de Divorcio en Chile. Santiago: Establecimientos Gráficos "Balcells \& Co".

\section{Fuentes secundarias}

\section{a) Artículos y capítulos de libros}

Amaro, L. (2012). "Estrategias del yo: construcción del sujeto autorial en los textos de cinco autobiógrafas chilenas", en Literatura y Lingüística, № 26, pp. 15-28.

Araya, C. (2006). "La construcción de una imagen femenina a través del discurso médico ilustrado. Chile en el siglo XIX", en Historia, XXXIX, Vol. I, enero-junio, pp. 5-22.

Bergot, S. (2018). "El servicio doméstico como mediador del escándalo: aproximación a través de un caso de adulterio, Santiago de Chile, 1874-1875", Nuevo Mundo Mundos Nuevos. En http://journals.openedition.org/nuevommundo, revisado el 20-XII-2018.

Cerón, J. (2918). "Escándalo y locura en la élite chilena: el asesinato de Teresa Zañartu, 1905", Nuevo Mundo Mundos Nuevos. En http://journals.openedition. org/nuevommundo, revisado el 20-IV-2018.

Devillard, M. (1995). "Individuo, sociedad y antropología social", en Revista Española de Antropología Americana, № 25, pp. 223-238.

De Blic, D. y C. Lemieux (2005). "Le scandale comme épreuve. Éléments de sociologie pragmatique", en Politix, Revue des Sciences Sociales du Politique, Vol. 71, N¹8, pp. 9-38.

Doll, D. (2007). "Desde los salones a la sala de conferencias: mujeres escritoras en el proceso de construcción del campo literario en Chile", en Revista Chilena de Literatura, $N^{\circ} 71$, pp. 83-100.

Fernández, P. (2014), "Mediadoras de la intimidad, negociadoras del escándalo: las domésticas en la novela naturalista radical de fin de siglo", en Cuadernos de Ilustración y Romanticismo, Revista Digital del Grupo de Estudios del Siglo XVIII, $N^{\circ} 20$, pp. 127-142.

Gayol, S. (2004). "Honor Moderno: The significance of honour in fin-de-siècle Argentina", en Hispanic American Historical Review, Vol. 84, №3, pp. 475-498.

Hagerman, A. (1978). "Impact of market agriculture on family and household structure in Nineteenth-century Chile", en Hispanic American Historical Review, Vol. 58, N4, pp. 625-648.

Jiménez, F. (1994). "Posibilidades y límites del escándalo político como una forma de control social", en Reis, N66, pp.7-36. 
Kottow, A. (2013). "Feminismo y femineidad: escritura y género en las primeras escritoras feministas en Chile", en Atenea, № 508, pp. 151-169.

Langue, F. (1995). "Les identités fractales: honneur et couleur dans la société vénézuélienne du XVIIle siècle", en Caravelle, № 65, pp. 23-37.

Piccato, P. (1999). "Politics and the Technology of Honour: Duelling in Turn-ofthe-Century Mexico", en Journal of Social History, Vol. 33, № 2, pp. 331-354.

Piccato, P. (2004). "Jurados de imprenta en México: el honor en la construcción de la esfera pública, 1821-1882", en Construcciones impresas. Panfletos, diarios y revistas en la formación de los estados nacionales en América Latina, 1820-1920, Buenos Aires, F.C.E., pp. 139-166.

Sagredo, R. (2006). "Nacer para morir o vivir para padecer. Los enfermos y sus patologías", en R. Sagredo y C. Gazmuri (Dirección). Historia de la vida privada en Chile. Tomo II El Chile moderno. De 1840 a 1925, Santiago de Chile: Taurus, pp. 10-57.

Salinas, R. e I. Goicovic (1997). "Amor, violencia y pasión en el Chile tradicional 1700-1850", en Anuario Colombiano de Historia Social y de la Cultura, № 24, pp. 237-268.

Salinas, R. (2000). "Fama pública, rumor y sociabilidad", en Lo público y lo privado en la historia americana, Santiago: Fundación Mario Góngora, pp. 133-154.

Salinas, R. (2000) "Violencias sexuales e interpersonales en Chile tradicional", en Revista de Historia social y de las Mentalidades, №4, invierno, pp. 13-49.

Salinas, R. (2008). "Violencia interpersonal en una sociedad tradicional. Formas de agresión y de control social en Chile: siglo XIX", en Revista de Historia Social y de las Mentalidades, № XII, Vol. 2, pp. 9-22.

Schillagi, C. (2011). "Problemas públicos, casos resonantes y escándalos. Algunos elementos para una discusión teórica", en Polis, Vol. 10, N³, pp. 245-266.

Traverso, A. (2012). "Primeras escritoras en Chile y autorización del oficio literario", en Anales de Literatura Chilena, Año 13, № 17, pp. 61-80.

Undurraga, V. (2016). "De coléricas a nerviosas. Emociones femeninas y sus ejes de comprensión. Chile, 1840-1890", en M. L. Candau (Editora). Las mujeres y las emociones en Europa y América. Siglos XVII-XIX, Santander: Editorial de la Universidad de Cantabria, pp. 383-410.

Undurraga, V. (2018). "La muerte social de Luis Matta Pérez. Escándalo y deshonor en Santiago de Chile a fines del siglo XIX", en Nuevo Mundo Mundos Nuevos. En http://journals.openedition.org/nuevomundo/72195, revisado el 20-XII-2018. 
Undurraga, V. y S. Bergot (2018). "Administrando el escándalo: honor y reputación en Chile, 1840-1920", en Nuevo Mundo Mundos Nuevos. En http://journals. openedition.org/nuevomundo/72193, revisado el 20-XII-2018.

\section{b) Libros}

Austin, J.L. (1962). How to do things with words. USA: Harvard University Press. Batticuore G. (2005). La mujer romántica. Lectoras, autoras y escritores en la Argentina: 1830-1870. Buenos Aires: Edhasa.

Bourdieu, P. (1991). El sentido práctico. Madrid: Taurus Humanidades.

Burke, P. y R. Po-Chia (2010). La traducción cultural en Europa moderna. Madrid: Akal.

Butler, J. (1993). Bodies that Matter: on the Discursive Limits of Sex. London: Routledge.

Castillo, A. y V. Sierra (Directores) (2014a). Cartas-Lettres-Lettere. Discursos, prácticas y representaciones epistolares (siglos XIV-XX). Alcalá de Henares: Universidad de Alcalá, Servicio de Publicaciones.

Castillo, A. y V. Sierra (Directores) (2014b). Cinco siglos de cartas. Historia y prácticas epistolares en las épocas moderna y contemporánea. Huelva: Universidad de Huelva.

Caulfield, S., S. Chambers y L. Putnam (Editores) (2005). Honor, Status, and Law in Modern Latin America. Durham NC: Duke University Press.

Caulfield, S. (2000). In Defense of Honor: Sexual Morality, Modernity, and Nation in Early-Twentieth-Century Brazil. Durham, N.C: Duke University Press.

Cavieres, E. y R. Salinas (1991). Amor, sexo y matrimonio en Chile tradicional. Valparaíso: U. Católica de Valparaíso.

Chambers, S. (1999). From Subjects to Citizens. Honour, gender and politics in Arequipa, Peru, 1780-1854, University Park: The Pennsylvania State University Press.

Chartier, R. (1994). El orden de los libros: lectores, autores, bibliotecas en Europa entre los siglos XVI y XVIII. Barcelona: Gedisa, 1994.

Chartier, R. (2000). Entre poder y placer. Cultura escrita y literatura en la Edad Moderna. Madrid: Cátedra.

Escriche, J. (1891). Diccionario razonado de legislación y jurisprudencia. Paris: Librería de Garnier Hermanos.

Fernández, M. (2011). Amor a palos: la violencia en la pareja en Santiago (19001920). Santiago: LOM Editores. 
Figueroa, P. P. (1897). Diccionario biográfico de Chile (tomo II). Santiago, Chile: Imprenta I Encuadernación Barcelona.

Figueroa, V. (1929). Diccionario Histórico Biográfico y Bibliográfico de Chile, 1800-1928, (Tomo III). Santiago, Chile: Imprenta Balcells.

Frevert, U. (2011). Emotions in History Lost and Found. Budapest: Central European University Press.

Frevert, U. et al. (2014). Emotional Lexicons. Continuity and change in the vocabulary of Feeling, 1700-2000. Oxford: Oxford University Press.

Gayol, S. (2008). Honor y duelo en la Argentina moderna. Buenos Aires: Siglo XXI Editores.

Gayol, S. (2000). Sociabilidad en Buenos Aires. Hombres, honor y cafés 18621910. Buenos Aires: Eds. Del Signo.

Goody, J. (1996) (Compilador). Cultura escrita en sociedades tradicionales. Barcelona: Gedisa.

Goody, J. (1993). The Interface Between the Written and the Oral. Cambridge: Cambridge University Press.

Johnson, L. y Lipsett-Rivera, S. (Editores) (1998). The faces of honor. Sex, shame and violence in Colonial Latin America. Albuquerque: University of New Mexico Press.

Levi, G. (1990). La herencia inmaterial. La historia de un exorcista piamontés del siglo XVII. Madrid: Nerea.

Marcus, D. (2009). Scandal \& Civility. Journalism and the Birth of American Democracy. Oxford: Oxford University Press.

Montero, C. (2018). Y también hicieron periódicos. Cien años de prensa de mujeres en Chile. 1850-1950. Santiago: Hueders.

Olson, D. y N. Torrance N. (Editores). Literacy and Orality. Cambridge: Cambridge University Press.

Ong, J. (2006). Oralidad y escritura. Tecnologías de la palabra. Buenos Aires: Fondo de Cultura Económica.

Picatto, P. (2010). The Tyranny of Opinion. Honor in the Construction of the Mexican Public Sphere. Durham: Duke University Press.

Rama, A. (1984). La ciudad letrada. Hanover: Ediciones del Norte.

Rengifo, F. (2011). Vida conyugal, maltrato y abandono. El divorcio eclesiástico en Chile, 1850-1890. Santiago de Chile: Editorial Universitaria. 
Rosenwein, B. (2006). Emotional Communities in the Early Middle Ages. Ithaca: Cornell University Press.

Teitelbaum, V. (2008). Entre el control y la movilización: honor, trabajo y solidaridades artesanales en la Ciudad de México a mediados del siglo XIX. México D.F.: El Colegio de México.

Undurraga, V. (2012). Los rostros del honor: normas culturales y estrategias de promoción social en Chile colonial, siglo XVIII. Santiago: Editorial Universitaria.

Whipple, P. (2013). La gente decente de Lima y su resistencia al orden republicano. Lima: IEP.

c) Tesis

Bergot, S. (2013). Entre "pouvoir" et "devoir". Dynamiques internes et construction sociale d'une famille de l'élite chilienne: le cas des Errázuriz Urmeneta, 18561930, Tesis para optar al grado de Doctorado en Historia, Pontificia Universidad Católica de Chile. 